\title{
College Students' Caffeine Intake Habits and Their Perception of Its Effects
}

\author{
Andrea R. Van Beek ${ }^{1}$, Megan E. Weier ${ }^{1}$, Kassandra R. Williams ${ }^{1}$, Samuel P. Abraham ${ }^{1}$ \& Deborah R. Gillum ${ }^{1}$ \\ ${ }^{1}$ Bethel University School of Nursing, Mishawaka, Indiana, USA \\ Correspondence: Samuel P. Abraham, Bethel University School of Nursing, 1001 Bethel Circle, Mishawaka, \\ Indiana, 46545. E-mail: samuel.abraham@betheluniversity.edu
}

Received: May 30, 2019

Accepted: June 18, 2019

Online Published: July 10, 2019

doi:10.20849/jed.v3i2.607

URL: https://doi.org/10.20849/jed.v3i2.607

\begin{abstract}
Background: Caffeine is a highly used stimulant on college campuses. The prevalence of energy drinks, especially among the younger generations is cause for concern. Purpose: The purpose of this study was to determine the caffeine intake habits of college students and the perception of its effects. Method: The method used was quantitative, cross-sectional, with a descriptive design. The two research questions were: (1) What are the caffeine intake habits of college students? (2) What are the perceptions of the effects of caffeine use among college students? This study was conducted at a college campus in northern Indiana, USA. Participants included 120 male and female students ages 18 years and older. The health belief model was used to guide this study. Results: The study indicated that while caffeine is a commonly used stimulant across campus, overuse was not revealed. Many students reported being able to go 48-72 hours without caffeine and not experiencing withdrawal symptoms when going without it. However, most students do report that they perceive a need to decrease their use of caffeine, as caffeine use has increased since attending college. Conclusion: The review of the literature indicated that the use of caffeine was higher in younger people. However, the research completed as a part of this study from college students indicated that caffeine overuse may not be as prevalent as previously thought.
\end{abstract}

Keywords: caffeine habits, effects, college students, benefits, risks, caffeinated beverages, perception of caffeine intake

\section{Introduction}

Caffeinated beverages have been a common commodity on college campuses for many years. It is well-known that caffeine is a heavily sought-after substance to provide energy for students to meet the expectations of their collegiate demands (Manchester, Eshel, \& Marion, 2017). Students seek out caffeine for the immediate effects that it bears, such as enhanced mood, alertness, ability to stay awake when fatigued, faster information processing, and heightened awareness (Richards \& Smith, 2015). Studies have reflected that following the ingestion of a caffeine-containing beverage, some people exhibit increased memory performance and function in executive tasks (Manchester et al., 2017). Caffeine has been relied upon by many who need an extra boost of energy. Mahoney et al. (2018) found that caffeine was consumed by $92 \%$ of students in the past year with a mean daily caffeine consumption of $159 \mathrm{mg} / \mathrm{d}$ and a mean intake of $173 \mathrm{mg} / \mathrm{d}$. Those who are consuming high levels of caffeine may not know the long-term effects it has on the body. Based on the review of the literature, a gap was detected regarding the effects of caffeine use among college students. The purpose of this quantitative study was to determine the caffeine intake habits of college students and their perception of its effects.

\subsection{Background}

Caffeine is a commonly used stimulant, yet it is often overlooked as being harmful to the body. Many studies have concluded that there are many unhealthy side effects that occur with the use of caffeine. Kadey (2016) warned that cardiovascular complications, insomnia, poor dietary choices, risky behavior, 'sugar blues,' and dental problems are some of the many potential harms of caffeine. These side effects can also be responsible for creating other health concerns after years of use.

College campuses are one area that is well-known for the use and overuse of caffeine. Many college students use caffeine to accomplish everything they need to do without thinking about the harm that it may be doing to their 
body. While grabbing a cup of coffee, tea, or other caffeinated beverages on the way to class seems like a harmless choice, side effects may be sneaking up behind the unsuspecting student (Kadey, 2016).

The Center for Disease Control and Prevention (CDC, 2018) has addressed the effects of alcohol and caffeine consumed together. "When alcohol is mixed with caffeine, the caffeine can mask the depressant effects of alcohol, making drinkers feel more alert than they would otherwise. As a result, they may drink more alcohol and become more impaired than they realize, increasing the risk of alcohol-attributable harms" (p. 6). The fact sheet continues to indicate how caffeine has no effect on the metabolism of alcohol by the liver, how it does not reduce blood or breath alcohol concentrations, and it does not reduce impairment due to alcohol consumption (CDC, 2018).

\subsection{Research Questions}

Two research questions addressed this study:

RQ1: What are the caffeine intake habits of college students?

RQ2: What are the perceptions of the effects of caffeine use among college students?

\section{Review of the Literature}

Peer-reviewed, full-text, articles were found using One Search, the Cumulative Index to Nursing and Allied Health Literature (CINAHL), Medline FULL-TEXT, and Nursing @ Ovid. The articles were located using keywords such as caffeine habits, effects, college students, benefits, risks, caffeinated beverages, and perception of caffeine intake. Most of the studies used for this proposal were published from 2015-2018 with the exception of Jiang's study which was conducted in 2014.

\subsection{Energy Drinks and Sleep Quality}

Faris et al. (2017) examined the occurrence of caffeinated energy drink consumption and its association with sleep quality in college students. The study revealed that $41 \%$ of students were consuming energy drinks regularly. "Approximately half of the students had normal sleep patterns; the other half had sleep problems (anxiety and intermittent sleep). Results revealed a significant $(\mathrm{r}=-.10, \mathrm{P}<.05)$ relationship between the consumption of energy drinks and sleep quality and patterns." This study showed that consumption of energy drinks is significantly associated with changes in sleep quality and patterns of students (Faris et al., 2017).

\subsection{Energy Drinks and Young Adults}

In another study, García et al. (2017) attempted to "determine the acute effects of a variety of recognized energy drinks on medical students, based on the hypothesis that these beverages may affect negatively cardiovascular parameters, stress levels, and working memory. Evaluations were performed before and following the intake of either carbonated water or one of three energy drinks containing caffeine in similar concentrations and an undetermined energy blend." Thirty-minute systolic blood pressure readings increased significantly in two of the groups tested. Heart rate showed an increase in the percent change in the other group. Cortisol salivary levels also increased. The authors determined that "consumers needed to be more informed about the safety of these energy drinks, especially the young student population" (García et al., 2017).

Manchester et al. (2017) discussed the growing popularity of energy drinks among society. However, concerns have been raised by some military leaders regarding the potential adverse effects of energy drinks. Manchester et al. warned that the combination of ingredients in caffeinated beverages could potentially do more harm than good. In addition to an increased intake of caffeine, there has also been an increase in the combination of alcohol and energy drink consumption, which may lead to serious health concerns. Manchester et al. reported a need for the public to have more knowledge about energy drinks and what they truly do to the body. Manchester et al. concluded that more studies need to be conducted to determine what risks and benefits there are to energy drinks and whether there needs to be regulations or policies regarding their use.

\subsection{Caffeine Association With Stress, Anxiety, and Depression}

The purpose of Richard and Smith's (2015) study was to investigate and assess the associations between caffeine consumption and stress, anxiety, and depression. The population used for their study was secondary school children from the South West of England. The participants varied between two cross-sections. The first cross-section cohort (T1) included a total of 3,071 students; however, only 2,610 agreed to participate in the study, which was an average of eighty-six percent. The second cross-section cohort (T2) included a total of 3,323 students; however, only 2,307 agreed to complete the questionnaires. Researchers maintained a reasonably balanced sex ratio and included an age range of eleven to seventeen years of age, with a mean of thirteen years of age. Richards and Smith used the Diet and Behavior Scale (DABS), which is a twenty-nine-item questionnaire 
that assesses the common dietary variables, with a focus on functional foods or foods and beverages of concern (i.e. caffeinated beverages). Eighteen questions included within the DABS assesses the frequency of caffeine consumption.

The study concluded that there were many positive associations between caffeine intake, and anxiety, and depression in this population. It also differed between boys and girls. Caffeine consumption was associated with anxiety in males but there was no observation for this in females. The effects of depression were seen in both sexes yet appeared lower in males than it was in females (Richards \& Smith, 2015).

\subsection{Caffeine and Myocardial Blood Flow}

Caffeine has various effects on different body systems. Van, Ties, Kuijpers, and Oudkerk (2018) discussed caffeine as being "a well-recognized antagonist of adenosine and a potential cause of false-negative functional measurements during vasodilator myocardial perfusion. The purpose of this systematic review was to summarize the evidence regarding the effects of caffeine intake on myocardial perfusion in patients with suspected coronary artery disease" (CAD). The authors concluded that recent caffeine ingestion has the potential to affect clinical decision making. The available data indicated a significant influence of recent caffeine intake on cardiac perfusion measurements (Van et al., 2018).

\subsection{Caffeine Withdrawal}

Mills, Dar-Nimrod, and Colagiuri (2017) conducted a study to determine genetic information and the caffeine content of a beverage on caffeine withdrawal in individuals. They investigated "if (1) being informed that one has tested positive for a gene related to caffeine withdrawal can produce an exaggerated caffeine withdrawal response during abstinence; (2) if one believes that they have consumed caffeine leads to a reduction in withdrawal symptoms when no caffeine is consumed" (Mills et al., 2017, p. 1). The study found that "participants who were told the coffee was caffeinated reported a greater reduction in withdrawal symptoms than those who were told it was decaffeinated" (Mills et al., 2017). These results could have indicated that the effects of caffeine are psychological in nature rather than physiological.

\subsection{Caffeine and Diabetes}

Jiang, Zhang, and Jiang (2014) found a relationship between coffee and caffeine intake and the incidence of type 2 diabetes mellitus (T2DM). In this study, the participants were given coffee in increments of two cups per day. Upon comparing the results among different populations including males and females, smokers and non-smokers, and other groups based on body mass index (BMI), Jiang et al. found that "Coffee and caffeine intake might significantly reduce the incidence of T2DM" (p. 25).

In another study, Santos and Lima (2016) researched the relationships between caffeine, diabetes, and obesity. They found that, "there is mounting evidence of the reduced risk of developing type 2 diabetes by regular coffee drinkers of 3-4 cups a day. The effects are likely due to the presence of chlorogenic acids and caffeine" (p. 1355).

\subsection{Caffeine and Physical Performance}

Energy drinks (EDs) are widely used around the world, especially by athletes involved in vigorous training. Drinks that increase energy and replenish electrolytes are often consumed quickly before athletes may realize the negative effects of these beverages. Polito, Souza, Coso, and Casonatto (2017) studied the effects of energy drink consumption on physical performance. The method used involved administering energy drinks to some participants and placebo or control drinks to the remaining participants. Polito et al. (2017) concluded, "The present review and meta-analysis showed that ED intake improved performance in several physical and sport situations that included muscle strength protocols, jumping, endurance exercise tests, and sport-specific action, and taurine dosage influenced the outcome" (p. 26). However, like the previous studies, this topic needs further testing and research to compile a more comprehensive study.

\subsection{Summary of the Literature Review}

There is a knowledge gap in the perception of caffeine in college students and the effects on the human body. More research is needed in this area. The reviewed studies indicated the prevalence of energy drinks, especially among the younger generations. The consumption of energy drinks is increasing and there is a need for education among the younger population, as caffeine creates different effects on the human body. Although energy drinks may appear to have positive effects, the prior studies indicated that there is a need to question the negative results from excessive caffeine consumption. 


\subsection{Theoretical Framework}

The theoretical framework used to guide this study was the health belief model (HBM). This model was initially published in 1974 by Rosenstock. The HBM is based on the understanding that "a person will take a health-related action if that person feels that a negative health condition can be avoided, has a positive expectation that by taking a recommended action, he/she will avoid a negative health condition, and believes that he/she can successfully take a recommended health action" (Rosenstock, 1974). This theory was connected to the study by determining the participants' health beliefs of their caffeine intake and the perception of its effects.

\subsection{Definition of Terms}

\subsubsection{Conceptual}

The HBM outlined by Rosenstock (1974) provides definitions for the conceptual terms used. "Perceived susceptibility is the belief about getting a disease or condition. Perceived severity is the belief about the seriousness of the condition or leaving it untreated and its consequences. Perceived benefits are the beliefs about the potentially positive aspects of health action. Perceived barriers are the beliefs about the potential negative aspects of particular health action. Self-efficacy is the belief that one can achieve the behavior required to execute the outcome. Cues to action are factors which trigger action" (Rosenstock, 1974).

\subsubsection{Operational}

Caffeinated beverages are any beverages that contain stimulant properties such as coffee, sports drinks, energy drinks, and soda. Caffeine intake habits are the typical behaviors of consumption, including the amount and type of caffeinated beverage. College students are any traditional students of ages 18 years and older who are enrolled at the college. Perception of caffeine intake is the participant's understanding of caffeine intake and the effects caffeine has on the body.

\section{Methodology}

\subsection{Method and Design}

The research method was quantitative, descriptive, and non-experimental. This method allowed for diversity among the surveys as it included participants from a variety of backgrounds. Quantitative research was the best method for this study because it incorporates a larger sample which may better represent college students and the diversity among the population. The survey instrument was given to all participants in the same context and setting and with the same instructions. Prior to study, the researchers completed the National Institute of Health (NIH) web-based training course "Protecting Human Research Participants." Approval from the Institutional Review Board was obtained prior to data collection.

\subsection{Sampling and Geographic Location}

The convenience sample included 120 male and female college students ages 18 years and over, excluding senior nursing students. The surveys did not contain participant names or identifying information. All incomplete surveys were shredded and were not included in the data analysis. The researchers conducted surveys in the lobbies of the Dining Commons and the library.

\subsection{Survey Instrument}

The survey was developed based on a thorough review of the literature. The process of survey development came from group input and different themes that have been prominent throughout the literature. The survey contained ten statements [1-10] regarding the participants' caffeine intake and ten statements [11-20] regarding their perception of its effects. This approach was appropriate because it assigned a nominal measurement to the results given. The results were calculated and easily compared. The survey results were measured by mean and the standard deviation. Scores were designated as strongly disagree scores as (1), disagree as (2), agree (3), and strongly agree (4).

\subsection{Instrument Reliability and Validity}

This quantitative survey was a new tool developed after a thorough review of the literature. The reliability of the tool was not established. This instrument was reviewed by two peers and two professors to establish face-validity. Schmidt and Brown (2019) defined face-validity as, "a test for content validity when colleagues or subjects examine an instrument and are asked whether it appears to measure the concept" (p. 266).

\subsection{Informed Consent and Confidentiality}

The informed consent includes the study title, purpose of the study, names of researchers, and the name of the institution it is conducted under. It also includes the voluntary option, why they were chosen, option for 
withdrawal, and assurance of no penalization for withdrawal. The potential benefits of participating in this study were also included, and an assurance that there are no potential risks that could come to the participant by filling out the survey. The informed consent included what the participants were expected to do, the expected time commitment, an indication of use of data and confidentiality of data, and a statement that the participant has read and understood the explanation and that any questions have been answered. A section for signatures, date, and contact for future information from the researchers were included as well. All collected data for this research were submitted to the School of Nursing to be stored electronically for three years, then destroyed.

\section{Results}

The literature review that was previously conducted was the foundation for examining the results of this study. The health belief model was applied to this study by examining perceptions of college-aged students in relation to caffeine. The purpose of this study was to determine college students' caffeine intake habits and perception of its effects. There was an array of both positive and negative perceptions of the population of students on the college campus.

The data collection process was conducted at the College Dining Commons and the Library. The researchers set up a table in the entrance of the buildings to encounter the target population. As students entered the building, the researchers asked them to fill out the survey instrument and explained the informed consent form to them.

After the students completed the survey instrument and informed consent, the papers were separated into two folders: one containing the survey tools and the other containing the informed consent. Participants were offered candy in return for their participation in the study.

\subsection{Participant's Demographic Characteristics}

Table 1. Descriptive statistics for participant demographics and background

\begin{tabular}{|c|c|c|}
\hline Variable & f & $\%$ \\
\hline \multicolumn{3}{|l|}{ Gender: } \\
\hline Male & 56 & 46.7 \\
\hline Female & 64 & 53.3 \\
\hline \multicolumn{3}{|l|}{ Age Range: } \\
\hline 18-19 & 51 & 42.5 \\
\hline 20-21 & 45 & 37.5 \\
\hline $22-23$ & 17 & 14.2 \\
\hline 24 and above & 7 & 5.8 \\
\hline \multicolumn{3}{|l|}{ Ethnicity: } \\
\hline Caucasian & 97 & 80.8 \\
\hline Hispanic & 9 & 7.5 \\
\hline African-American & 8 & 6.7 \\
\hline Native American & 2 & 1.7 \\
\hline Other & 4 & 0.03 \\
\hline \multicolumn{3}{|l|}{ Year in School: } \\
\hline Freshman & 49 & 40.8 \\
\hline Sophomore & 13 & 10.8 \\
\hline Junior & 29 & 24.2 \\
\hline Senior & 29 & 24.2 \\
\hline \multicolumn{3}{|c|}{ Number of Caffeinated Drinks Daily } \\
\hline o (None) & 61 & 50.8 \\
\hline $1-2$ & 49 & 40.8 \\
\hline 3-4 & 7 & 5.8 \\
\hline $5-6$ & 3 & 2.5 \\
\hline
\end{tabular}

Note. $(\mathrm{N}=120)$. 
The participants in this study were college students, ages 18 and above. One hundred and twenty students participated and successfully completed the study. Table 1 contains the demographic data of the participants including the variable surveyed, the frequency $(f)$, and the percentage (\%). This includes gender, age range, ethnicity, year in school, and a number of caffeinated drinks daily.

The statistics from the demographic was heavier in certain areas than in others. Fifty-six females (46.7\%) and sixty-four men (53.3\%) completed surveys. The most common age range was 18-19, with $51(42.5 \%)$ students who participated. The second common age range was 20-21 with $45(37.5 \%)$ students, followed by 17 students within the 22-23 range (14.2\%) and 7 students within the 24 and above range (5.8\%). The most common ethnicity surveyed was Caucasian with 97 students $(80.8 \%)$. There were 9 Hispanic students $(7.5 \%), 8$ African-American students (6.7\%), 2 Native American students (1.7\%), and one Asian student (0.8\%). Three students identified as other $(2.5 \%)$.

Within this study, there were 49 freshmen surveyed (40.8\%). Junior and senior students both counted 29 students for each class $(24.2 \%$ each). Sophomore students had the least number of representatives with 13 students $(10.8 \%)$. The number of daily caffeinated drinks was also surveyed. Sixty-one students reported that they do not drink any throughout a typical day (50.8\%). However, 49 students reported drinking 1-2 caffeinated drinks daily (40.8\%). Seven students said they consume 3-4 drinks per day (5.8\%) and three reported 5-6 drinks per day $(2.5 \%)$.

\subsection{Item Set Description}

Table 2. Student caffeine intake habits

\begin{tabular}{ll}
\hline Variable & Mean \\
\hline I could go 48-72 hours without caffeine. & 3.39 \\
I drink caffeinated beverages for the taste more than the effects. & 2.43 \\
My caffeine consumption has increased since being at college. & 2.26 \\
I drink caffeine every day. & 2.13 \\
I've tried to quit consuming caffeine. & 2.10 \\
I drink caffeine before class. & 2.0 \\
I prefer a caffeinated beverage with a meal if given the option. & 1.92 \\
I find myself craving caffeine. & 1.89 \\
I binge drink caffeinated beverages when I am stressed. & 1.78 \\
I rely on caffeine to get me through the day. & 1.64
\end{tabular}

Note. $(\mathrm{N}=120)$. Items were rated on a 4-point Likert-type scale ranging from 1 (Strongly Disagree) to 4 (Strongly Agree), so higher means indicate higher levels of agreement.

\subsubsection{Research Question One}

The first research question asked was, "What are the caffeine intake habits of college students?" Survey items one through ten addressed this question. Students rated their response to each statement based on a four-point Likert-type scale, (1) meaning strongly disagree, (2) meaning disagree, (3) meaning agree, and (4) meaning strongly agree. In Table 2, the means $(M)$ are listed from highest to lowest with their corresponding standard deviation $(S D)$.

Based on the results, the participants had the highest agreement that they could go 48-72 hours without caffeine $(M=3.39, S D=.95)$. The participants rated high in regards to drinking caffeinated beverages more for the taste than for than the effects $(M=2.43, S D=1.03)$, that their caffeine consumption has increased since being at college $(M=2.26, S D=1.10)$, and that they drink caffeine every day $(M=2.13, S D=1.13)$. The participants rated the lowest in finding themselves craving caffeine $(M=1.89, S D=1.00)$, binge drinking caffeine when stressed $(M=1.78, S D=1.06)$, and relying on caffeine to get them through the day $(M=1.64, S D=.90)$. 
The results from college students' caffeine habits showed that most of them do not rely too heavily on the stimulant. A lot of the students reported drinking caffeinated drinks more for the taste than for the effects. However, many students reported increasing caffeine consumption since being at college and many reported drinking caffeine every day. This being said, there still was a majority of students who do not rely on caffeine to make it through their day.

\subsubsection{Research Question Two}

The second research question asked was, "What are the perceptions of the effects of caffeine use among college students?" Survey items eleven through twenty addressed this question. Students rated their response to each statement based on a four-point Likert-type scale, (1) meaning strongly disagree, (2) meaning disagree, (3) meaning agree, and (4) meaning strongly agree. In Table 3, the means $(M)$ are listed from highest to lowest with their corresponding standard deviation $(S D)$.

Based on the results, many of the students reported in high agreement that they should limit their caffeine intake $(M=2.7, S D=.77)$. The participants also reported in high numbers that caffeine helps them wake up $(M=2.3$, $S D=.98)$, that they cannot sleep after consuming caffeine $(M=2.28 S D=1.03)$, and that caffeine helps them focus $(M=2.2, S D=.98)$. The participants had the lowest ratings when asked if their caffeine intake was a problem $(M=1.6, S D=.72)$ and whether it is a priority for them to consume caffeine every day $(M=1.6, S D$ $=.85)$.

The results concluded that many college students do view their caffeine intake in a negative light. Many of the participants agreed that they should limit their caffeine intake. Many college students agreed that caffeine helps them wake up, focus, and that it makes it harder for them to fall asleep after consuming. However, many students agreed that it was not a priority for them to consume caffeine every day or that their intake was a problem. Contrary to reservations, the study did not indicate that the student population maintains an excessive use of caffeine or perception of overuse.

Table 3. Student perceptions of caffeine effects

\begin{tabular}{ll}
\hline Variable & Mean \\
\hline I should limit my caffeine intake. & 2.7 \\
Caffeine helps me wake up. & 2.3 \\
I cannot sleep after consuming caffeine. & 2.28 \\
Caffeine helps me focus. & 2.2 \\
Caffeine makes me more productive. & 2.18 \\
Caffeine has no negative effects. & 1.97 \\
Caffeine reduces my stress levels. & 1.88 \\
I experience headaches and withdrawal symptoms when I don't consume caffeine. & 1.8 \\
My caffeine intake is a problem. & 1.6 \\
It is a priority for me to consume caffeine every day. & 1.6
\end{tabular}

Note. $(\mathrm{N}=120)$. Items were rated on a 4-point Likert-type scale ranging from 1 (Strongly Disagree) to 4 (Strongly Agree), so higher means indicate higher levels of agreement.

\section{Discussion of Findings}

Previous literature discussed the effects of caffeine on the human body and that overuse of this stimulant could pose some serious health problems (Manchester et al., 2017). This raised concern as caffeine is a frequently utilized and overlooked stimulant. There was, however, a gap in the literature regarding the prevalence of caffeine use in the college population. This study addressed the caffeine intake habits of college students and whether they perceived it as a problem. The review of the literature suggested that the use of caffeine was higher in 18-24-year-old people. However, the surveys completed as a part of this study from college students indicated that caffeine overuse may not be as prevalent as previously thought. 


\subsection{What Are the Caffeine Intake Habits of College Students?}

The results of the study showed that on average, among the students surveyed, caffeine is not being overused (see Figure 1). The majority of students reported that they were confident they could go 48-72 hours without the use of caffeine. Many students even reported that they consume caffeine more for the taste of the beverage than for the stimulating effects. The study does imply, however, that the consumption of caffeinated beverages does increase since being at college with many students reporting that they drink caffeinated beverages daily.

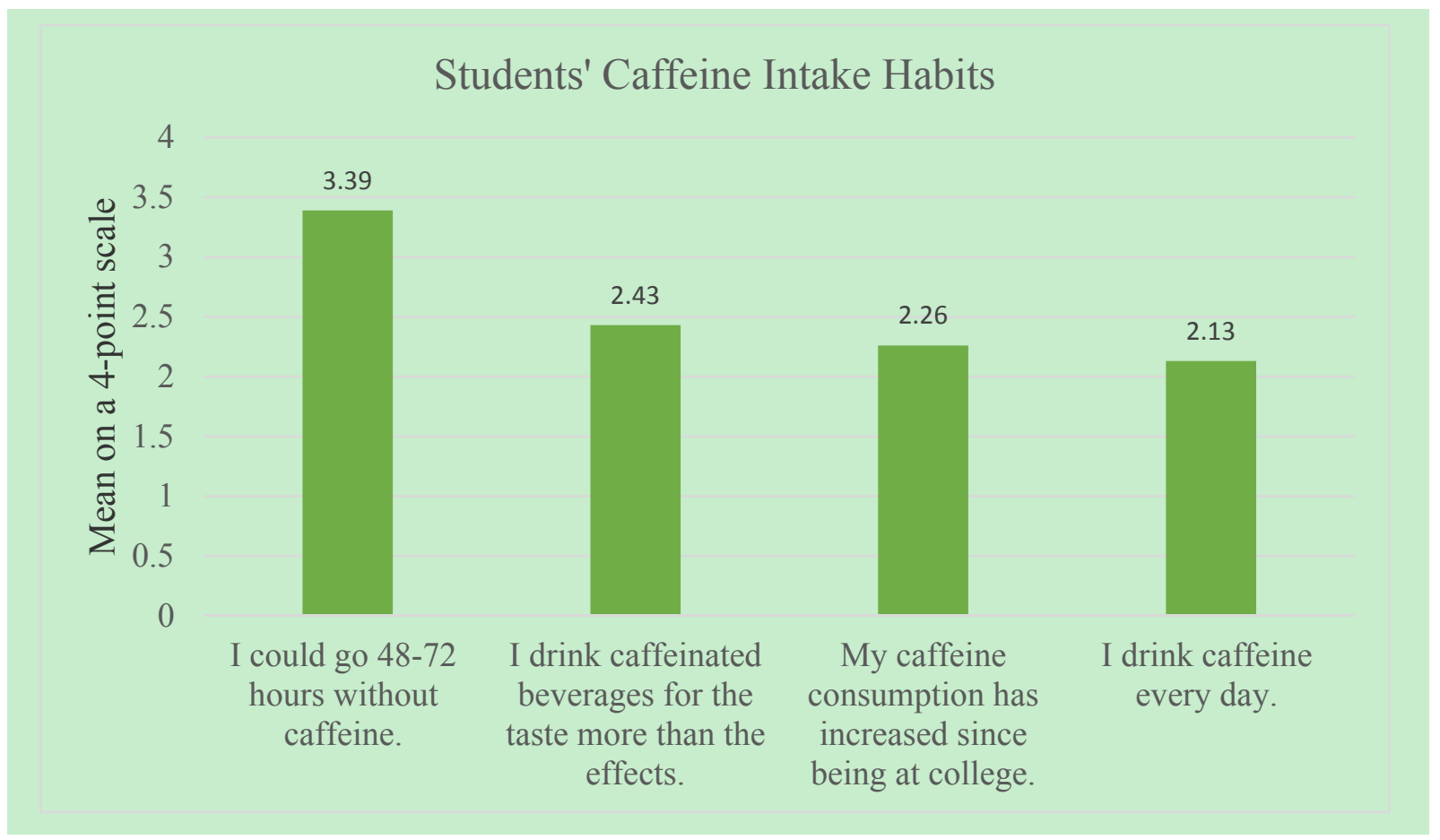

Figure 1. Top four mean and standard deviation results for students' caffeine intake habits

\subsection{What Are the Perceptions of the Effects of Caffeine Use Among College Students?}

The result of the perceptions portion of the study showed that many students do view their caffeine use in a negative light (see Figure 2). Many students reported that they feel a need to decrease their use of caffeine. The majority of students reported that the use of caffeine helps to wake them up in the morning, stay focused, and keeps them awake following consumption. Few students agreed that they experienced withdrawal symptoms without consistent caffeine intake. Mills, Dar-Nimrod, and Colagiuri (2017) reported that people who drink caffeine consistently or excessively typically exhibit withdrawal symptoms when they go without. According to the survey, this was not an issue for the majority of college students. The study also concluded that most students indicate that they do not feel it is a priority to consume caffeine daily and that they do not feel that their caffeine use is a problem. 


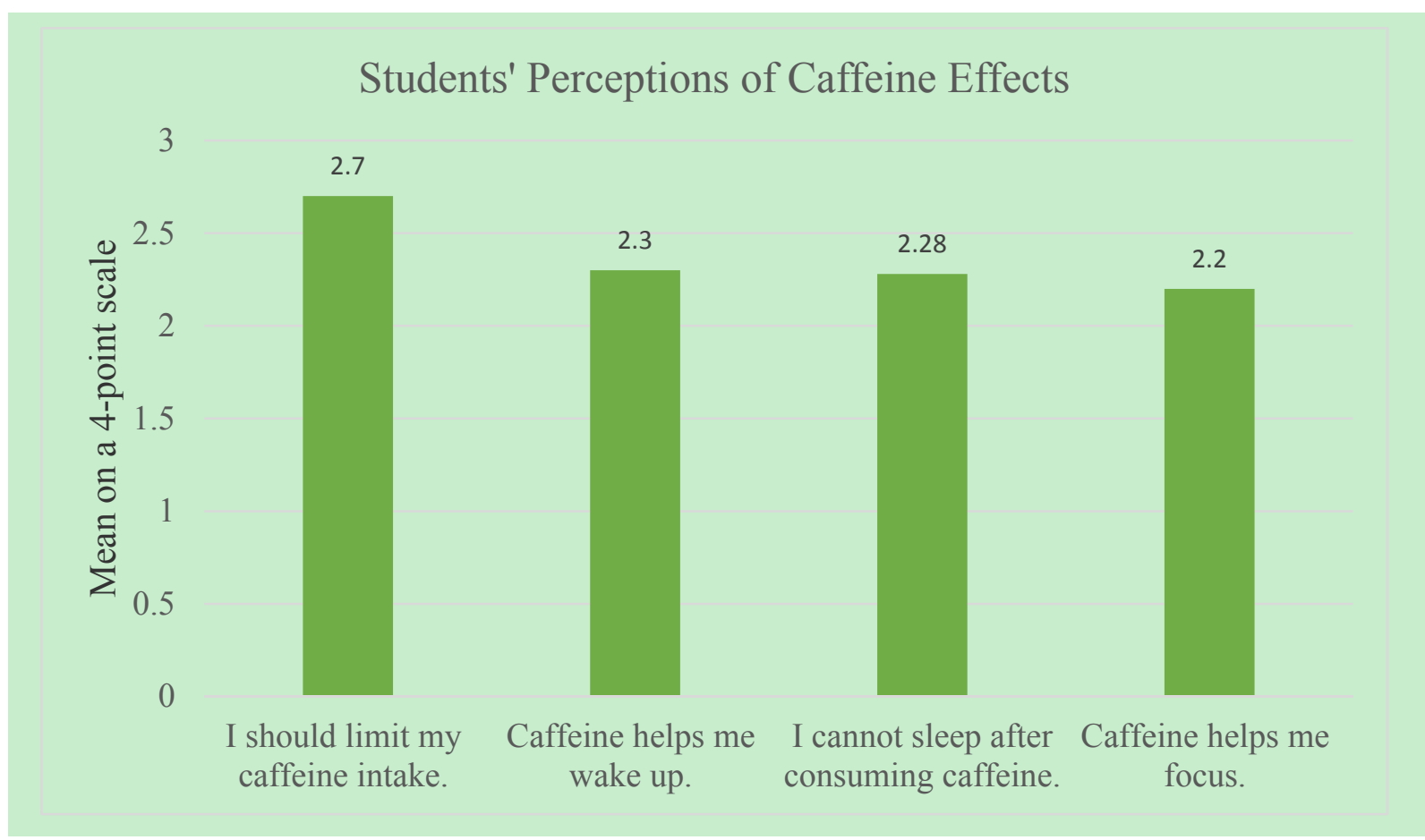

Figure 2. Top four mean for students' perceptions of caffeine effects

\section{Limitations}

Only 120 individuals were surveyed, which was a limitation as it is a smaller group of participants. Only students attending one college were surveyed which limits the diversity of the answers as it was a limited population of students. The data was only being collected outside the Dining Commons and the library, which was a limitation. Participants were not screened for use of any stimulants outside of caffeine. Participants' involvement in energy-requiring activities that would cause an increased desire for caffeine consumption were not assessed. Though face-validity was obtained, the survey did not have established reliability and validity was another limitation to this study.

\section{Implications}

Caffeine is a drug that is often overlooked by many. This study may impact the nursing and college communities by creating an increased awareness and understanding of the effects that caffeine has on the body. This study can help colleges and universities gain an understanding of the common caffeine intake habits and its effects. Clinical settings can use this information to understand the aggregate community of college-age students when they are seen in healthcare. Caffeine can potentially affect certain health tests and measures. Healthcare professionals should be aware of caffeine and the health risks related by many.

\section{Conclusion}

Despite detecting a gap in the literature, this study indicated that caffeinated beverages have multiple effects on an individual's body. Overall, the results indicated that caffeine is indeed a commonly used stimulant among college students. Many students view their intake as a problem but use it for the effects gained. Proper education and awareness regarding caffeine use would be beneficial.

\section{Recommendations}

Every study has factors upon which could be improved that are typically realized after the study has been completed. This study is no exception; the researchers observed some things that could have been changed to potentially improve the outcome of the study. To improve the outcomes of future studies on this topic, the researchers have some recommendations. Recommendations for future studies first include using a survey instrument that has proven reliability and validity. Secondly, collecting data from larger sample size and from additional locations. Utilizing data from more participants would give a more accurate overall look at the student population, and using other locations. 


\section{References}

Center for Disease Control and Prevention. (2018). Fact sheets- alcohol and caffeine. Retrieved from https://www.cdc.gov/alcohol/fact-sheets/caffeine-and-alcohol.htm

Faris, E., Jahrami, H., Al, H. M., Chehyber, N. J., Ali, S. O., Shahda, S. D., \& Obaid, R. S. (2017). Energy drink consumption is associated with reduced sleep quality among college students: A cross-sectional study. Nutrition \& Dietetics, 74(3), 268-274. https://doi.org/10.1111/1747-0080.12289

García, A., Romero, C., Arroyave, C., Giraldo, F., Sánchez, L., \& Sánchez, J. (2017). Acute effects of energy drinks in medical students. European Journal of Nutrition, 56(6), 2081-2091. https://doi.org/10.1007/s00394-016-1246-5

Jiang, X., Zhang, D., \& Jiang, W. (2014). Coffee and caffeine intake and incidence of type 2 diabetes mellitus: A meta-analysis of prospective studies. European Journal of Nutrition, 53(1), 25-38. https://doi.org/10.1007/s00394-013-0603-x

Kadey, M. (2016, January). Caffeine overdrive. Environmental Nutrition, 39(1), 4. Retrieved from https:/universityhealthnews.com/topics/nutrition-topics/caffeine-overdrive/

Mahoney, C., Giles, G., Marriot, B., Judelson, D., Glickman, E., Geiselman, P., \& Lieberan, H. (2018). Intake of caffeine from all sources and reasons for use by college students. Clinical Nutrition, 1-8. https://doi.org/10.1016/j.clnu.2018.04.004

Manchester, J., Eshel, I., \& Marion, D. W. (2017). The benefits and risks of energy drinks in young adults and military service members. Military Medicine, 182(7). https://doi.org/10.7205/milmed-d-16-00339

Mills, L., Dar-Nimrod, I., \& Colagiuri, B. (2017). Effect of genetic information and information about caffeine content on caffeine withdrawal symptoms. Scientific Reports, $7(1)$. https://doi.org/10.1038/s41598-017-08678-4

Polito, M., Souza, D., Coso, J., \& Casonatto, J. (2017). Acute effects of caffeine-containing energy drinks on physical performance: A systematic review and meta-analysis. European Journal of Nutrition, 56(1), 13-27. https://doi.org/10.1007/s00394-016-1331-9

Richards, G., \& Smith, A. (2015). Caffeine consumption and self-assessed stress, anxiety, and depression in secondary school children. Journal of Psychopharmacology, 29(12), 1236-1247. https://doi.org/10.1177/0269881115612404

Rosenstock, I. M. (1974). The health belief model and preventive health behavior. Health Education Monographs, 2(4), 354-386. https://doi.org/10.1177/109019817400200405

Santos, R., \& Lima, D. (2016). Coffee consumption, obesity and type 2 diabetes: A mini review. European Journal of Nutrition, 55(4), 1345-1358. https://doi.org/10.1007/s00394-016-1206-0

Schmidt, N. A., \& Brown, J. M. (2019). Evidence-based practice for nurses (4th ed.). Burlington, MA: Jones \& Bartlett Learning.

Van, D., Ties, D., Kuijpers, D., \& Oudkerk, M. (2018). Effects of caffeine on myocardial blood flow: A systematic review. Nutrients, 10(8). https://doi.org/10.3390/nu1008108

\section{Copyrights}

Copyright for this article is retained by the author(s), with first publication rights granted to the journal.

This is an open-access article distributed under the terms and conditions of the Creative Commons Attribution license (http://creativecommons.org/licenses/by/4.0/). 